\title{
Pengaruh Penggunaan Coolant 30/70 Pre-Mixed Dan Coolant Predilute 33\% Pada Sistem Pendingin Terhadap Temperatur Engine Toyota Avanza Tipe-E 1300 CC M/T
}

\author{
Suparno $^{1}$, Abd. Halim ${ }^{2 *}$, Hariadi $^{3}$, Didik Sutrisno ${ }^{4}$ \\ ${ }^{123}$ Jurusan Teknik Mesin, Politeknik Negeri Samarinda, Kalimantan Timur, 75131, Indonesia \\ ${ }^{4}$ Karyawan PT. Badak Natural Gas Liquefaction Bontang, Kalimantan Timur, 75324, Indonesia
}

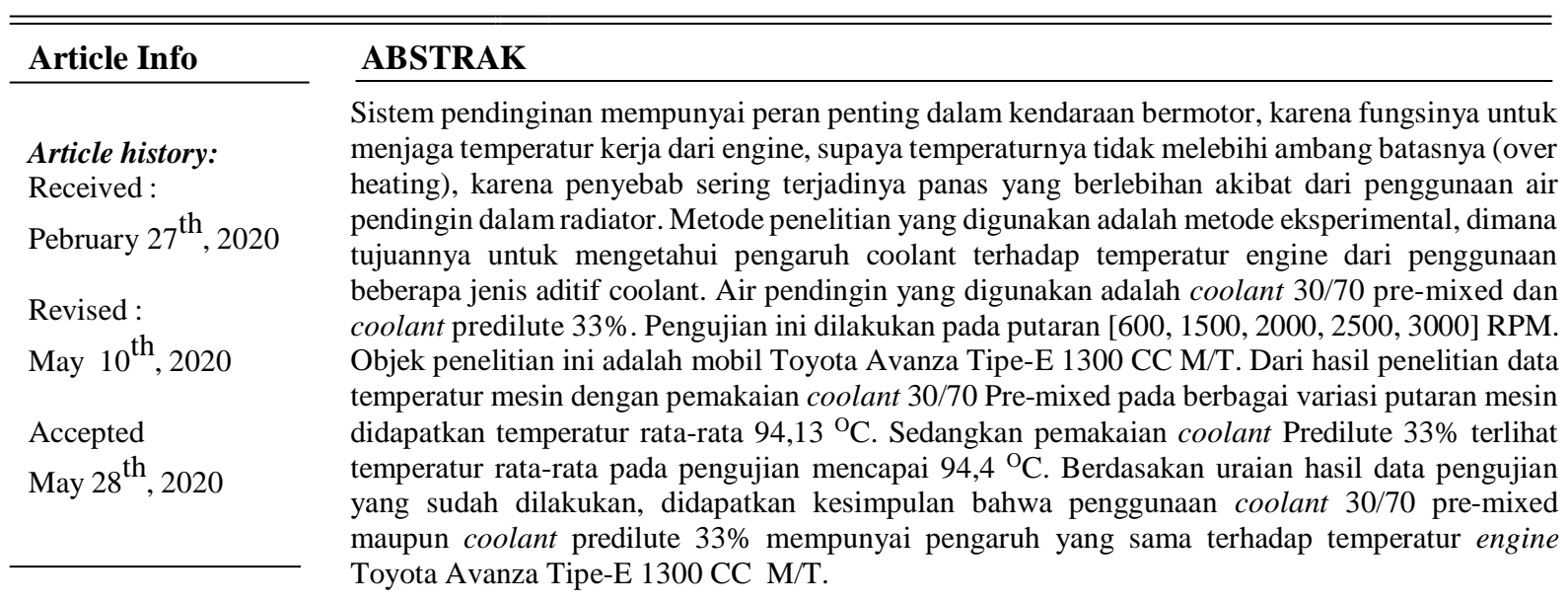

Kata kunci: Sistim Pendingin, Coolant, Temperatur engine, Toyota avanza

\begin{abstract}
ABSTRAK
Cooling system has an important role in motor vehicles, because its function is to maintain the working temperature of the engine, so that the temperature does not exceed the threshold (over heating), due to the frequent causes of excessive heat due to the use of cooling water in the radiator. The research method used is an experimental method, where the aim is to determine the effect of coolant on engine temperature from the use of several types of coolant additives. The cooling water used is coolant $30 / 70$ pre-mixed and coolant predilute $33 \%$. This test is carried out at rounds of [600, 1500, 2000, 2500, 3000] RPM. The object of this research is the Toyota Avanza Type E 1300 $C C M / T$. From the results of research on engine temperature data with the use of coolant 30/70 Pre-mixed at various variations of engine speed obtained an average temperature of $94.13{ }^{\circ} C$. While the use of coolant predilute $33 \%$, the average temperature in testing reaches $94.4{ }^{\circ} \mathrm{C}$. Based on the description of the results of the test data that has been done, it was concluded that the use of coolant 30/70 pre-mixed and coolant predilute 33\% has the same effect on the temperature of the Toyota Avanza Type-E 1300 CC M/T engine.
\end{abstract}

Keywords: Cooling system, Coolant, Engine temperature, Toyota Avanza

Corresponding Author:

Abd. Halim

Department of Mechanical Engineering

Politeknik Negeri Samarinda,

Jl, Ciptomangunkusumo Kampus Gunung Lipan, Samarinda 75131, Indonesia

Email: halim72@polnes.ac.id 


\section{PENDAHULUAN}

Kemajuan teknologi bidang otomotif berkembang sangat pesat mendorong manusia untuk selalu mempelajari ilmu pengetahuan dan teknologi. Dalam dunia otomotif khususnya pada mesin motor bakar dikenal berbagai macam sistem yang bekerja. Sistem-sistem tersebut bekerja saling berkaitan antara satu dengan yang lainnya, sehingga apabila salah satu dari sistem tersebut mengalami kerusakan, maka mesin mobil akan mengalami kerusakan. Mesin dapat digambarkan secara sederhana sebagai sebuah sistem yang terdiri dari beberapa sistem pendukung yang bekerja secara simultan dan terintegrasi. Suatu mesin didalamnya terdapat beberapa sistem pendukung yang bekerja sekaligus. Sistem-sistem tersebut antara lain sistem kelistrikan; sistem bahan bakar; sistem pelumasan; sistem pendinginan dan sistem pemasukan dan pembuangan udara.

Sistem pendinginan (cooling system) adalah suatu rangkaian untuk mengatasi terjadinya over heating pada mesin agar mesin dapat bekerja secara optimal. Sistem pendinginan berfungsi sebagai absorber panas yang dihasilkan oleh mesin yang berasal dari proses pembakaran dalam silinder, panas ini tentunya sangat mengganggu jika dibiarkan begitu saja karena akan menimbulkan over heating, hal tersebut menjadi suatu perhatian karena temperatur yang berlebihan akan cenderung merubah sifat-sifat serta bentuk dari komponen mesin tersebut. Bila sifat serta bentuk komponen telah berubah dipastikan kinerja mesin akan terganggu sehingga kinerja mesin tidak akan bekerja secara maksimal, yang pada gilirannya usia mesin tidak akan lama. Sering kita lihat kejadian di jalan, radiator sebuah mobil berasap sehingga mengakibatkan mobil tersebut mogok, juga banyak sekali kejadian water pump dan radiator bocor, blok mesin dan cylinder head keropos, atau gasket hancur.

Masalah ini tidak hanya memerlukan biaya yang cukup tinggi tetapi juga menyita tenaga dan waktu yang sangat berharga. Jika temperatur mesin terlalu tinggi, maka mesin akan mengalami overheating dan tidak bisa bekerja normal. Untuk itu perlu suatu sistem penjaga temperatur mesin agar tak sampai melebihi temperatur tersebut. Untuk menjaga performa mesin kendaraan dalam keadaan baik, maka diperlukan perawatan dan perbaikan yang rutin serta perhatian yang seksama terrhadap mesin kendaraan. Salah satu hal yang diperhatikan adalah sistem pendingan mesin atau cooling system pada mesin mobil. Berkaitan dengan sistem pendinginan ini, hal yang diperhatikan salah satunya adalah pemilihan jenis air pendingin, yaitu dengan memilih air pengisi radiator yang efektif dan ekonomis, tujuannya agar performa mesin kendaraan selalu dalam kondisi baik dan prima.

Penelitian terkait dengan penggunaan jenis coolant yang berbeda beberapa tahun terakhir. Penggunaan coolant yang memiliki titik didih yang lebih tinggi daripada titik didih air berpengaruh signifikan terhadap efektivitas radiator engine diesel [1]. Dan tingkat panas tertinggi setelah diambil rata-rata dari setiap putaran mesinnya adalah terletak pada penggunaan air biasa [2]. Perbedaan pengaruh jenis fluida pendinginan terhadap kapasitas radiator (Q) sangat berpengaruh terhadap sistem pendinginan [3]. Dan beberapa penelitian yang melakukan untuk mengetahui seberapa besar pengaruh sistem pendingin terhadap perputaran mesin baik pada saat kondisi pompa normal maupun pada saat kondisi tidak normal [4].

Pemakaian air radiator saat ini diharapkan tak hanya sebagai penjaga kestabilan temperatur mesin saja, akan tetapi juga mampu menghindari permasalahan-permasalahan yang timbul pada sistem pendingin diantaranya masalah korosi / karat terhadap dinding mesin dan cylinder head mesin, serta rongga-rongga pada radiator itu sendiri, sehingga mesin menjadi awet pemakaiannya. Diantara spesifikasi coolant yang banyak digunakan, ada 2 coolant yang ingin penulis uji. Dua tipe coolant itu ialah coolant 30/70 pre-mixed dan coolant predilute 33\%.

Berdasarkan latar belakang yang telah diuraikan, permasalahan yang akan diungkapkan dalam penelitian ini adalah: Apakah ada pengaruh penggunaan jenis coolant yang berbeda terhadap perubahan temperatur engine Toyota Avanza Tipe-E $1300 \mathrm{CC}$ M/T. Tujuan yang diharapkan dari penelitian ini adalah untuk mengetahui pengaruh coolant 30/70 pre-mixed terhadap temperatur engine Toyota Avanza Tipe-E 1300 CC MT dengan variasi putaran engine $(600,1500,2000,2500,3000) \mathrm{rpm}$ dan untuk mengetahui pengaruh coolant predilute $33 \%$ terhadap temperatur engine Toyota Avanza Tipe-E 1300 CC MT dengan variasi putaran engine [600, 1500, 2000, 2500, 3000] RPM.

\section{Kajian Teoritis}

Defenisi Temperatur Kerja Mesin [5] dalam bukunya mengatakan "Temperatur adalah suatu penunjukan nilai panas atau nilai dingin yang dapat diperoleh/diketahui dengan menggunakan suatu alat yang dinamakan termometer. Termometer adalah suatu alat yang digunakan untuk mengukur dan menunjukkan besaran temperatur. Tujuan pengukuran temperatur adalah untuk : mencegah kerusakan pada alat-alat tersebut, mendapatkan mutu produksi/kondisi operasi yang diinginkan, dan pengontrolan jalannya proses. Hugh D Young (2002) dalam bukunya mengatakan : "Konsep suhu (temperature) berakar dari ide kualitatif 'panas' dan 'dingin' yang berdasarkan pada indera sentuhan kita. Suatu benda yang terasa panas umumnya mimiliki suhu yang lebih tinggi daripada benda serupa yang dingin. Hal ini tidak cukup jelas, dan indera dapat dikelabui. Tetapi banyak sifat benda yang dapat diukur tergantung pada suhu. Panjang batang logam, tekanan uap dalam boiler, kemampuan suatu kawat mengalirkan arus listrik, dan warna suatu benda panas yang berpendar, semua tergantung suhu". Dari beberapa kutipan diatas dapat disimpulkan bahwa Temperatur adalah ukuran panas-dinginnya dari suatu benda. 
Panasdinginnya suatu benda berkaitan dengan energi termis yang terkandung dalam benda tersebut. Makin besar energi termisnya, makin besar temperaturnya., yang pada pembahsan ini di arahkan pada sistem pendinginan mesin. Temperatur yang terjadi pada mesin saat operasi sangat tinggi, oleh karena itu dibutuhkan sistem pendinginan untuk menjaga temperatur ideal saat mesin beroperasi.

Media Pendingin Pendingin dalam kamus besar bahasa indonesia adalah alat untuk mendinginkan sesuatu. Dalam hal ini mempunyai pengertian, yaitu media atau alat pendingin untuk menurunkan temperatur bahan yang temperaturnya tinggi. [6] dalam bukunya mengatakan "in liquid-cooled system, water is generally used as a cooling medium. however, other liquid or a mixture of water and other liquids may also be used in the system to prevent freezing of the coolant at lower temperatures" [7] mengatakan "radiator coolant merupakan zat additive untuk fluida radiator. Fungsinya adalah untuk memperbesar koefisien perpindahan panas konveksi pada fluida kerja radiator sehingga laju pembuangan panas meningkat (penyerapan panas oleh fluida di water jacket lebih besar). Disamping itu untuk memperbesar laju perpindahan panas konveksi dari fluida ke permukaan luar radiator, kemudian meningkatnya konveksi ke udara luar sehingga panas yang terbuang menjadi lebih besar. Cairan pendingin umumnya berupa air atau oli. Antifreeze yang dicampurkan dalam coolant bertujuan untuk menurunkan titik beku. Sehingga coolant terkadang diartikan sebagai antifreeze, karena pada titik didih $100{ }^{\circ} \mathrm{C}$ air dianggap mudah menguap. Sebaliknya pada titik beku $0{ }^{\circ} \mathrm{C}$, air mudah membeku selain itu air membuat logam berkarat, dan meniggalkan bekas mineral yang yang mengurangi kemampuan pendinginannya. Untuk itulah beberapa bahan kimia ditambahkan pada coolant adalah gabungan antara bahan anti beku dan air, coolant bisa digunakan untuk menyerap panas per liter lebih dari cairan pendingin lain. Dibawah kondisi standar, air yang dipanaskan pada suhu 212 F dan yang dibekukan pada suhu 32 F. ketika air dibekukan, maka volume air itu bertambah sekitar $9 \%$. Perluasan dari pembekuan air bisa dengan mudah memecahkan/membuat keretakan pada bagian mesin, bagian atas selinder, dan radiator, semua perusahaan/produsen menyarankan untuk menggunakan ethylene glycol berbasis bahan anti beku yang digabungkan untuk perlindungan melawan masalah ini”. Dari beberapa kutipan diatas, dapat disimpulkan dalam hal ini media pada sistem pendingin merupakan suatu zat fluida yang mengalir dan memiliki fungsi untuk menjaga temperatur kerja mesin pada saat beroperasi.

\section{Hubungan Watercoolant dengan Temperatur Kerja Mesin}

Kemampuan sistem pendingin mesin dengan fluida cair (coolant) sangat tergantung pada kemampuan coolant menyerap sejumlah kalor dari mesin dan melepaskannya ke udara melalui radiator. Jumlah kalor yang dipindahkan meningkat sejalan dengan peningkatan perbedaan temperatur masuk dengan keluar radiator, panas jenis dan kapasitas coolant yang dialirkan. Pendinginan coolant dilakukan dengan mengalirkan udara diantara pipa-pipa aliran coolant pada radiator. "The coolant that courses through the engine and associated plumbing must be able to withstand temperatures well below zero without freezing. It must also be able to handle engine temperatures in excess of 250 degrees without boiling. A tall order for any fluid, but that is not all. The fluid must also contain rust inhibiters and a lubricant. The coolant in today's vehicles is a mixture of ethylene glycol (antifreeze) and water. The recommended ratio is fifty-fifty. In other words, one part antifreeze and one part water. This is the minimum recommended for use in automobile engines. Less antifreeze and the boiling point would be too low. In certain climates where the temperatures can go well below zero, it is permissible to have as much as $75 \%$ antifreeze and $25 \%$ water, but no more than that. Pure antifreeze will not work properly and can cause a boil over" [8]. Dari beberapa kutipan diatas dapat disimpulkan bahwa kandungan pada radiator coolant sangat berpengaruh terhadap temperatur kerja mesin. Karena viskositas antara air dan coolant berbeda pada struktur kimianya, oleh karena itu terdapat perbedaan kemampuan dalam mendingan temperatur kerja mesin pada saat mesin panas.

\section{METODOLOGI}

Metode dan desain eksperimen yang digunakan dalam penelitian ini adalah eksperimental dengan pendekatan menggunakan satu kali pengumpulan data pada suatu saat $[9,10]$. Pola pendekatan yang diambil ialah dimana pendekatan menggunakan beberapa kali pengumpulan data. Data tersebut diambil dari proses penelitian terhadap mesin Toyota Avanza Tipe-E 1300 CC M/T.

Penelitian yang dilakukan ini untuk mengetahui pengaruh penggunaan dua jenis cairan coolant yang berbeda terhadap temperatur engine. Penelitian ini dirancang sebagai berikut:

a. Obyek yang digunakan untuk penelitian adalah mobil Toyota Avanza Tipe-E 1300 CC M/T Tahun 2016.

b. Jenis coolant yang digunakan adalah coolant $30 / 70$ pre-mixed dan coolant predilute $33 \%$.

c. Putaran engine diatur pada kecepatan [600, 1500, 2000, 2500 dan 3000] RPM.

d. Holding time untuk pengambilan data temperatur adalah masing-masing 180 detik untuk pengujian dan diambil 3 kali pada tiap-tiap putaran engine. 
e. Menentukan titik tempat pengambilan temperatur yang diuji Th1 untuk temperatur inlet radiator, Th2 untuk temperatur outlet radiator dan Th3 untuk temperatur tercatat di engine scanner.

Variabel penelitian terdiri variabel bebas, variabel terikat dan variabel kontrol. Dimana variabel bebas adalah kondisi yang mempengaruhi munculnya suatu gejala. Dalam penelitian ini yang menjadi variabel bebas adalah 2 jenis coolant yaitu, coolant 30/70 pre-mixed dan coolant predilute 33\%, dan variabel terikat adalah himpunan sejumlah gejala yang memiliki sejumlah aspek atau unsur di dalamnya, yang berfungsi menerima atau menyesuaikan diri dengan kondisi variabel lain. Dalam penelitian ini variabel terikatnya adalah perbedaan temperatur engine Toyota Avanza. Sedangkan variabel kontrol merupakan himpunan sejumlah gejala yang memiliki berbagai aspek atau unsur di dalamnya, yang berfungsi untuk mengendalikan agar variabel terikat yang muncul bukan karena pengaruh variabel lain, tetapi benar-benar karena pengaruh variabel bebas yang tertentu. Variabel kontrol dalam penelitian ini adalah putaran mesin yaitu : [600, 1500, 2000, 2500, 3000] RPM.

Pada penelitian ini digunakan alat-alat dan bahan serta sarana pendukung untuk mendapatkan data-data yang diperlukan, meliputi mobil toyota avanza, engine scanner, stopwatch, thermometer infrared termal, toolbox set dan coolant yang akan diuji atau diteliti.

Tabel 1. Alat pendukung penelitian [Engine scanner, thermometer infrared thermal dan watch, engine]

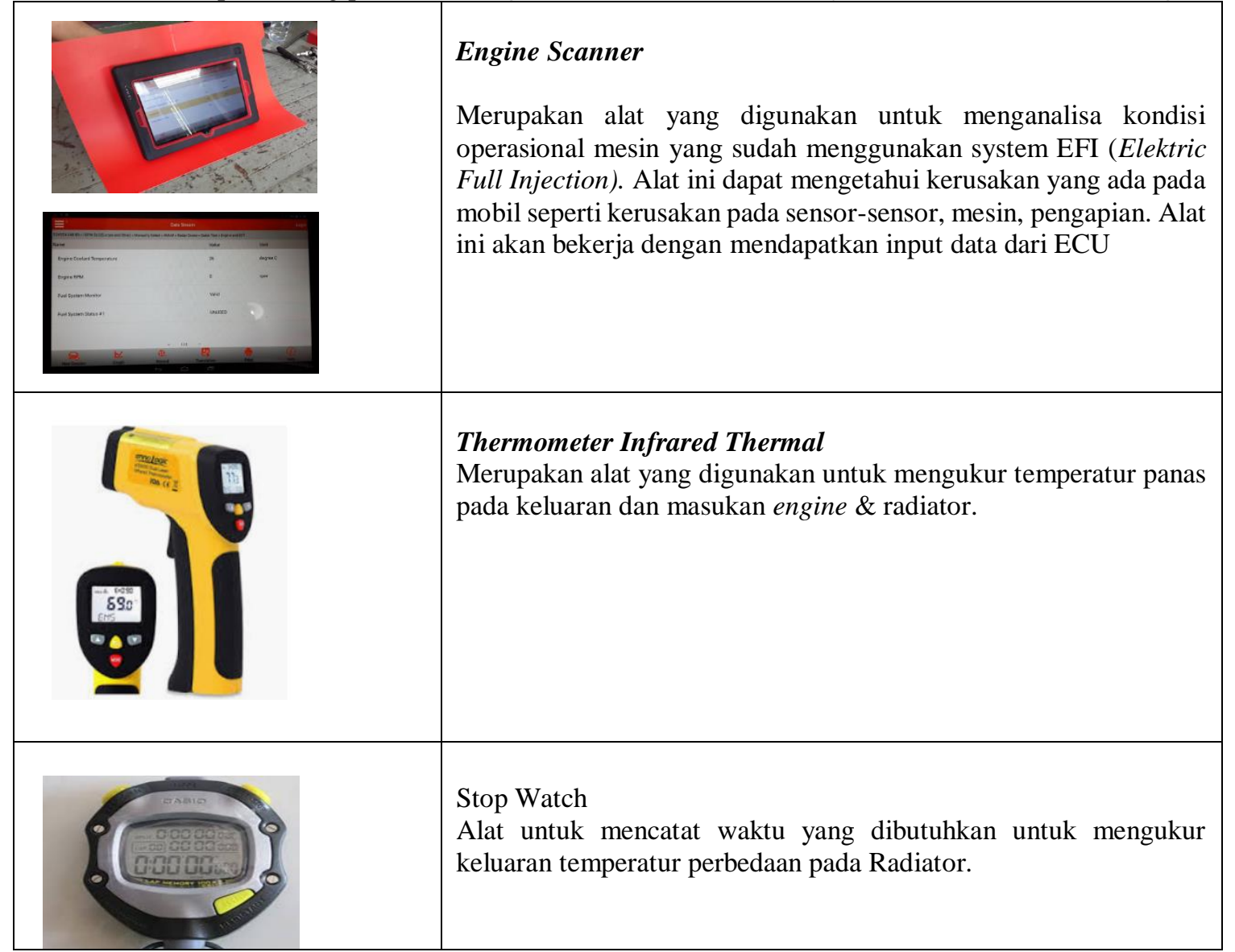




\begin{tabular}{|c|c|}
\hline 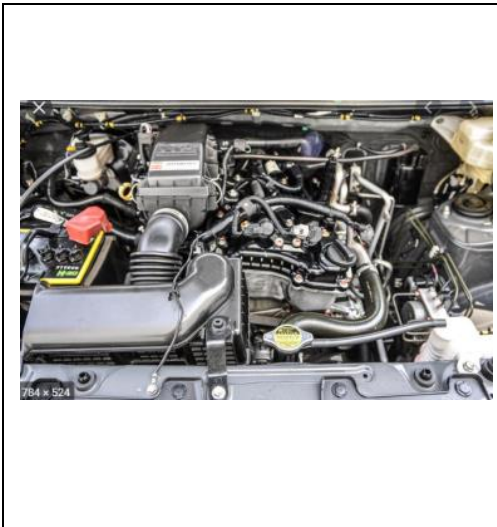 & $\begin{array}{ll}\begin{array}{l}\text { Spesifikasi Engine Toyota } \\
\text { Model }\end{array} & : \text { 1NR-VE Type-E 1300 CC M/T } \\
\text { Type Mesin } & : \text { 4 Cylinder, IL, 16 Valve DOHC, } \\
& \text { Chain Drive with Dual VVT-i } \\
\text { Transmisi } & : 5 \text { speed M/T } \\
\text { Displacement } & : 1329 \mathrm{CC} \\
\text { Compression Ratio } & : 11.5: 1 \\
\text { Max Output } & : 95 \mathrm{HP} / 6000 \mathrm{rpm} \\
\text { Max Torque } & : 121 \mathrm{Nm} / 4200 \mathrm{rpm} \\
\text { Fuel } & : \text { Gasoline } \\
\text { Fuel Supply system } & : \text { EFI (Electric Fuel Injection) } \\
\text { Ignition System } & : \text { Direct Ignition System } \\
\text { Fuel Tank Capacity } & : \text { 45 liters }\end{array}$ \\
\hline
\end{tabular}

Pada penelitian ini digunakan 2 coolant yang berbeda jenis yaitu coolant 30/70 pre-mixed dan coolant predilute $33 \%$. Coolant yang digunakan pada penelitian ini mempunyai karakteristik seperti yang tertera pada kemasannya yang dapat dijelaskan sebagai berikut:

a. Coolant 30/70 pre-mixed, adalah coolant berbasis etilen glikol, mengandung zat anti beku yang tahan hingga temperatur $-15^{\circ} \mathrm{C}$ selain itu juga mengandung zat anti korosi.
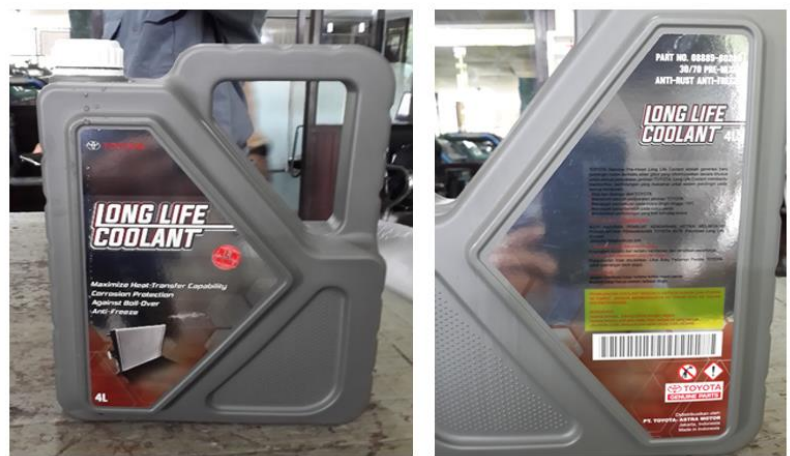

Gambar 1. Coolant 30/70 pre-mixed

b. Coolant predilute 33\%, adalah coolant yang mengandung ethylene glycol, diethylene glycol, sodium 2ethyl dan sodium neodecanoate. Mengandung zat anti beku hingga temperatur $-18{ }^{\circ} \mathrm{C}$, titik didih hingga $126{ }^{\circ} \mathrm{C}$. Juga mengandung zat anti korosi yang memenuhi ASTM D1384, D4340, D2809.
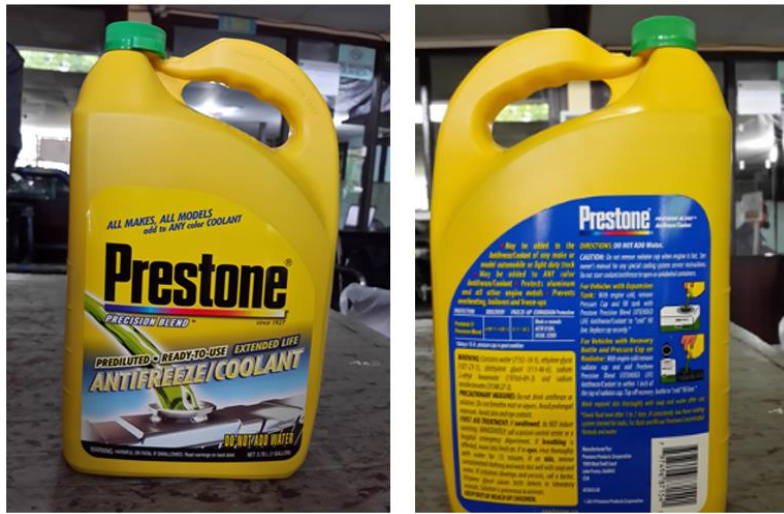

Gambar 2. Coolant predilute $33 \%$ 


\section{Tahapan Persiapan Penelitian}

Sebelum melakukan pengujian, peralatan serta komponen yang akan diuji harus diperiksa agar dapat dioperasikan dengan baik. Hal-hal yang harus dilakukan sebelum pengujian adalah sebagai berikut:

- Mempersiapkan alat-alat yang terdiri dari: engine scanner, thermometer infrared thermal, tool box, stopwatch,

- Coolant yang akan diuji sudah tersedia

- Teliti dan pastikan peralatan dan perangkat percobaan semua dalam kondisi siap pakai.

- Periksa kondisi radiator dan sistem pendingin dalam keadaan baik, tidak bocor.

- Periksa kondisi mesin dalam keadaan baik

- Periksa alat ukur engine scanner, thermometer infrared thermal dan stopwatch dalam kondisi baik.

\section{Tahapan Pelaksanaan}

Pengambilan data pengujian dilakukan satu persatu dengan jeda waktu untuk mendapatkan kondisi yang sama untuk tiap-tiap media yang diuji (coolant). Langkah-langkah yang harus dilakukan dalam pengambilan data pengujian untuk mendapatkan hasil yang memuaskan adalah sebagai berikut:

- Periksa dan isi sistem pendingin dengan coolant yang akan diuji sampai batas yang disarankan termasuk pada reservoir.

- Hidupkan mesin hingga mencapai temperatur kerja mesin.

- Naikkan putaran mesin (RPM) sesuai data yang ingin diambil

- Monitor temperatur mesin pada engine analyzer dan ukur temperatur coolant. Pengukuran menggunakan thermometer infrared thermal, pada bagian hose atas dan hose bawah radiator, proses ini dilakukan untuk membandingkan antara temperatur coolant yang diuji yaitu coolant 30/70 Pre-mixed dan coolant Predilute $33 \%$.

- Catat data yang didapat:

$\checkmark$ Temperatur Inlet Radiator $($ Th1 $)=$

${ }^{0} \mathrm{C}$

$\checkmark$ Temperatur Outlet Radiator $(\mathrm{Th} 2)=\ldots \ldots \ldots \ldots \ldots \ldots . .{ }^{0} \mathrm{C}$

$\checkmark$ Temperatur pada Engine Scanner $(\mathrm{Th} 3)=\ldots \ldots \ldots \ldots \ldots{ }^{0} \mathrm{C}$

- Jaga putaran mesin tetap stabil;

- Pertahankan kondisi putaran mesin selama waktu yang sudah ditentukan dan catat perubahan temperatur yang terjadi. Semua data yang diambil dimasukkan ke dalam tabel data (check sheet);

- Setelah pengambilan data selesai, langkah berikutnya penggantian coolant yang dilakukan setelah mesin mobil dalam kondisi total dingin;

- Mengisi sistem pendingin dengan coolant predilute 33\%;

- Ulangi lakukan langkah di atas untuk tiap kali pengambilan data tiap perbedaan putaran mesin.

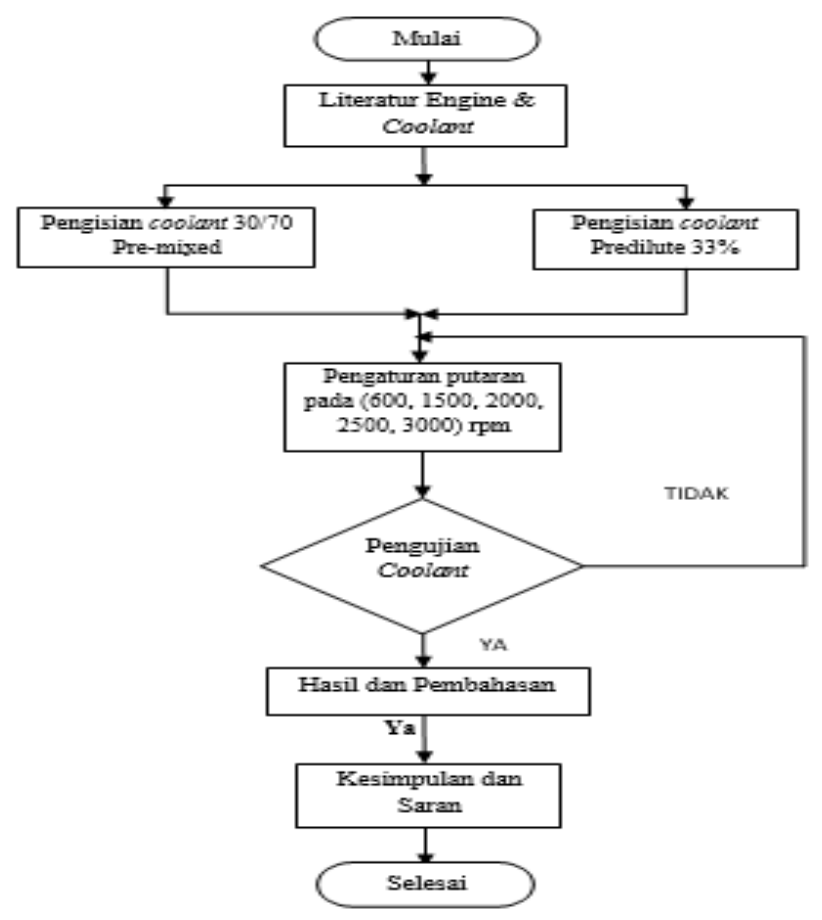

Gambar 3. Diagram alir penilitian 


\section{HASIL DAN PEMBAHASAN}

Dari data pengujian coolant 30/70 pre-mixed yang sudah didapatkan diatas, profile temperatur rata-rata disajikan seperti grafik di bawah.

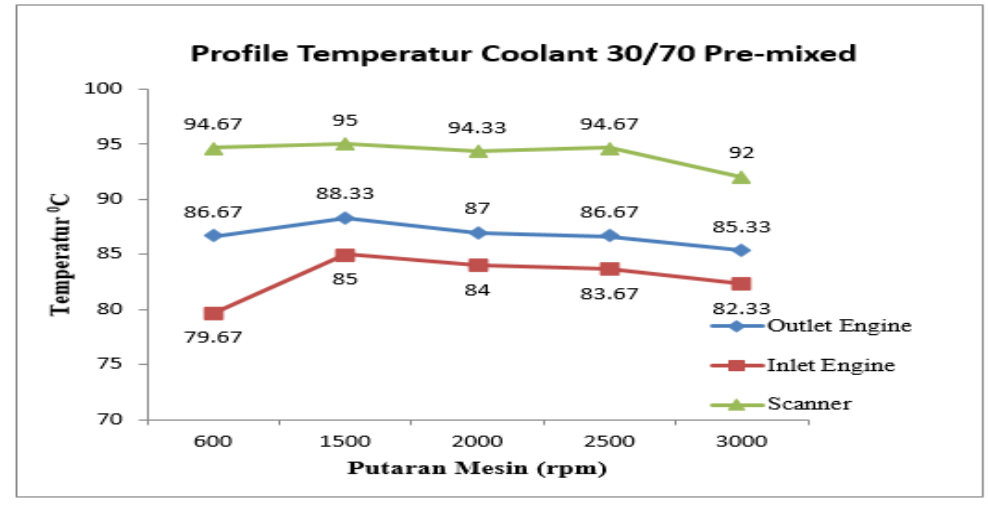

Gambar 4. Temperatur rata-rata coolant 30/70 pre-mixed

Berdasarkan uraian hasil eksperimen gambar 4, temperatur rata-rata seperti ditunjukan pada grafik untuk variasi rpm secara keseluruhan, terlihat bahwa temperatur coolant keluar engine mencapai nilai rata-rata $86{ }^{\circ} \mathrm{C}$, yang mana kondisi ini masih jauh dari titik didih air. Temperatur inlet engine atau outlet radiator ada kenaikan dari putaran $600 \mathrm{rpm}$ ke $1500 \mathrm{rpm}$ naik sekitar $5{ }^{\circ} \mathrm{C}$. Kondisi ini karena air pendingin mulai bersirkulasi dari mesin ke radiator. Setelah pendinginan oleh radiator temperature coolant mencapai rata-rata $83{ }^{\circ} \mathrm{C}$. Tempertur engine yang ditunjukan oleh engine scanner cukup stabil pada rata-rata temperature $94{ }^{\circ} \mathrm{C}$, bahkan pada putaran 3000 rpm temperatur engine mencapai $92{ }^{\circ} \mathrm{C}$. Hal ini menunjukan coolant 30/70 pre-mixed mampu menjaga temperatur engine tidak sampai overheating.

Dari data pengujian coolant predilute $33 \%$ yang sudah didapatkan diatas, profile temperatur rata-rata disajikan seperti grafik di bawah.

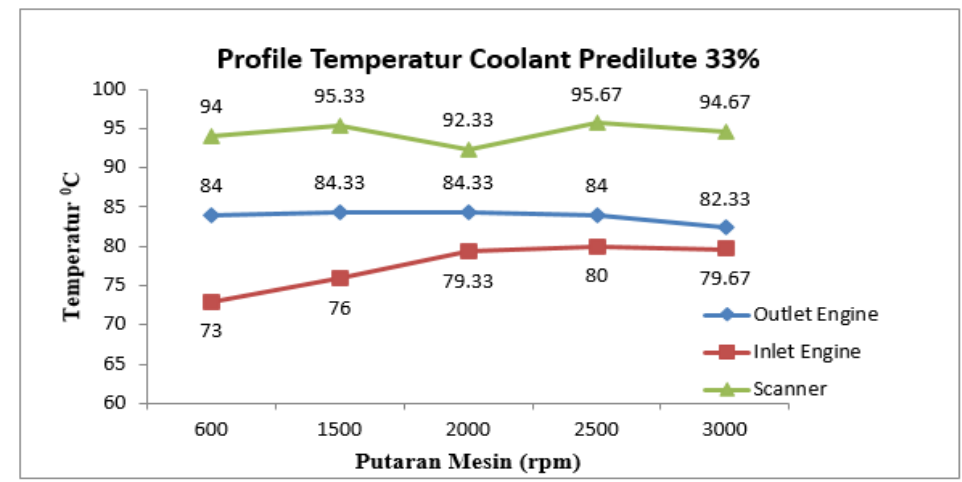

Gambar 5. Temperatur rata-rata coolant predilute $33 \%$

Dari gambar 5, grafik yang diperoleh dari hasil pengujian coolant predilute 33\% dapat dijelaskan bahwa pada putaran engine 600 - $3000 \mathrm{rpm}$ temperatur coolant outlet engine cukup stabil pada rata-rata $84{ }^{0} \mathrm{C}$. Temperatur yang tercatat pada engine scanner secara rata-rata $94{ }^{\circ} \mathrm{C}$. Sedangkan temperature inlet engine atau outlet radiator mulai stabil pada putaran 2000 - $3000 \mathrm{rpm}$ pada sekitar $79{ }^{\circ} \mathrm{C}$. Dari data table yang diperoleh dari pengujian masing-masing coolant, kemudian dibuat suatu grafik yang diambil dari nilai rata-rata temperatur pada masingmasing putaran mesin untuk masing-masing titik uji sebagai dasar untuk memberikan kemudahan menarik kesimpulan dari penelitian.

Grafik perbandingan temperatur outlet engine (Th-1) antara coolant 30/70 pre-mixed dan coolant predilute $33 \%$ seperti grafik berikut. 


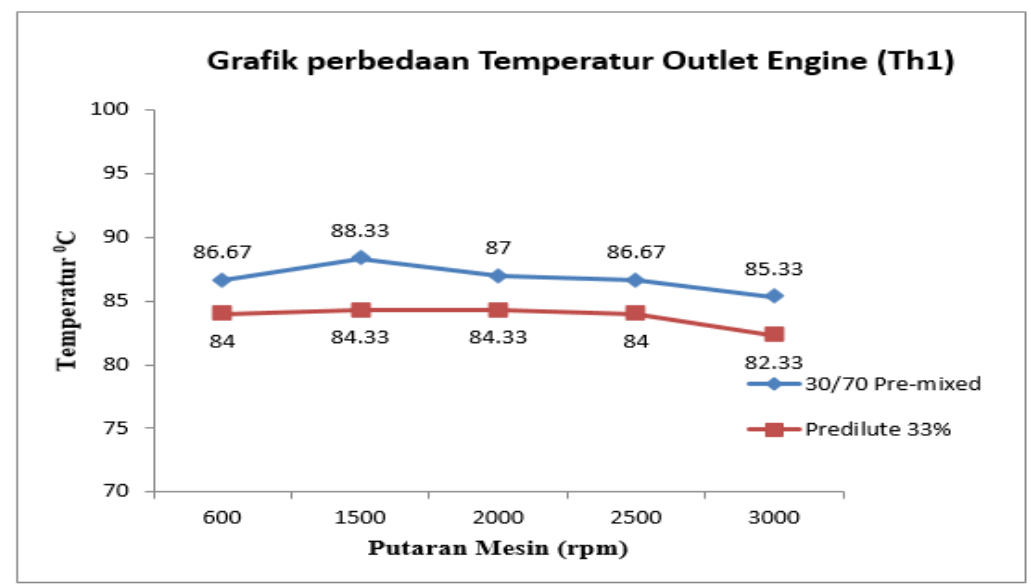

Gambar 6. Perbedaan temperatur outlet engine (Th1) coolant 30/70 pre-mixed dan coolant predilute $33 \%$

Berdasarkan grafik hasil eksperimen gambar 6, setelah menyerap panas mesin, coolant predilute $33 \%$ temperaturnya cukup steady pada sekitar $84{ }^{\circ} \mathrm{C}$ pada putaran mesin $600 \mathrm{rpm}$ hingga $2500 \mathrm{rpm}$, bahkan cenderung lebih dingin pada putaran mesin $3000 \mathrm{rpm}$ mencapai temperature $82{ }^{\circ} \mathrm{C}$. Sedangkan berdasarkan gambar grafik temperatur coolant 30/70 pre-mixed pada keluaran engine temperaturnya sedikit lebih panas bila dibandingkan dengan coolant predilute $33 \%$ yaitu mencapai rata-rata $87{ }^{\circ} \mathrm{C}$, pada putaran tertinngi $3000 \mathrm{rpm}$ temperaturnya mencapai $85{ }^{\circ} \mathrm{C}$.

Untuk melihat perbandingan kondisi temperatur mesin yang didinginkan dengan coolant 30/70 pre-mixed dan coolant predilute $33 \%$ dapat dilihat dari data engine scanner pada masing masing putaran mesin seperti pada grafik berikut,

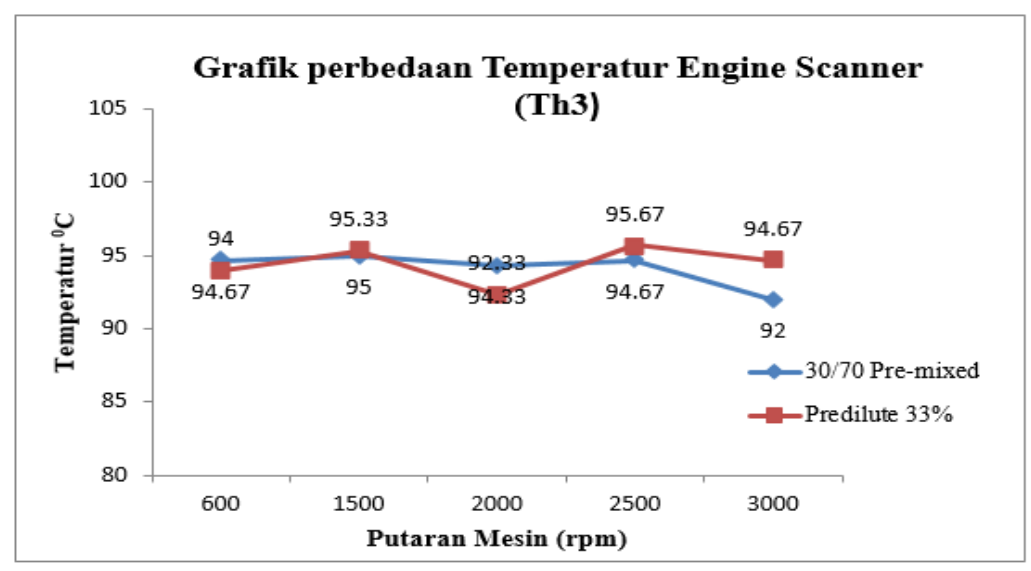

Gambar 7. Perbedaan temperatur engine scanner

Dari gambaran grafik 7, diatas, temperatur rata-rata mesin cenderung stabil dengan pemakaian coolant $30 / 70$ pre-mixed pada berbagai variasi putaran mesin. Sedangkan pemakaian coolant predilute $33 \%$ terlihat ada fluktuasi temperature pada putaran $2000 \mathrm{rpm}$, dimana temperaturnya mencapai $92{ }^{\circ} \mathrm{C}$. Namun temperatur engine dengan pendinginan coolant predilute $33 \%$ dicapai rata-rata $94{ }^{\circ} \mathrm{C}$. Kondisi ini kemungkinan dipengaruhi oleh perbedaan komposisi komponen kandungan masing-masing coolant.

Semakin tinggi putaran engine yang dihasilkan dari semakin besarnya pembakaran diruang bakar, maka semakin besar pula panas yang harus diserap oleh air pendingin. Perputaran engine yang tinggi juga mengakibatkan pompa air coolant bergerak cepat sehingga meningkatkan laju sirkulasi air pendingin yang bergerak mengelilingi water jacket, sehingga menyebabkan konveksi yang terjadi pada water jacket dan radiator semakin besar pula. Temperatur air pendingin yang keluar dari engine dan mengalir menuju radiator untuk didinginkan selanjutnya 
mengalir kembali ke mesin sebagai pendingin dengan bantuan pompa sirkulasi yang terhubung dengan poros putaran mesin. Grafik temperatur coolant keluar radiator atau masuk mesin seperti di bawah :

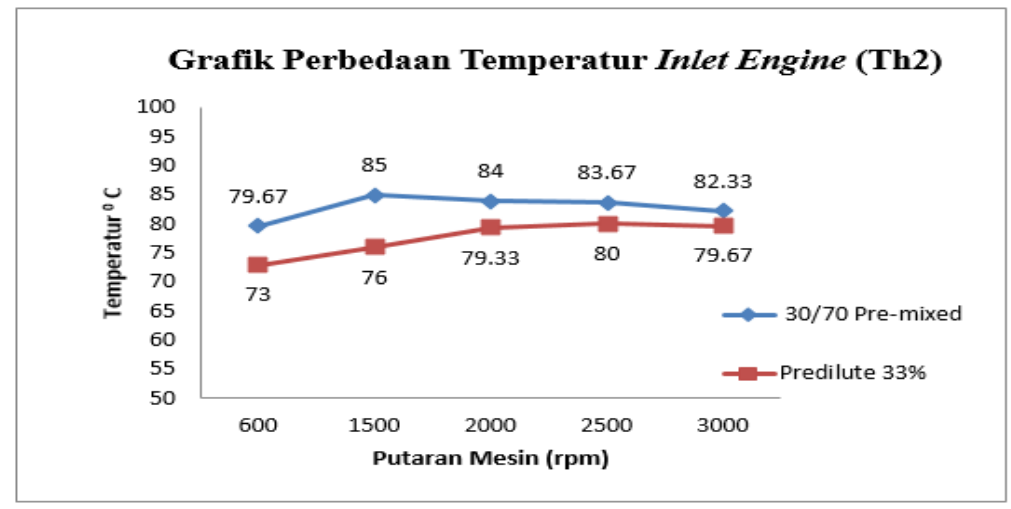

Gambar 8. Perbedaan temperatur inlet engine coolant 30/70 pre-mixed dan coolant predilute $33 \%$

Berdasarkan gambar 8 menunjukkan temperatur air pendingin coolant 30/70 pre-mixed yang keluar dari radiator pada putaran engine $600 \mathrm{rpm}$ ke $1500 \mathrm{rpm}$, ada peningkatan temperatur dari $79{ }^{\circ} \mathrm{C}$ hingga $85{ }^{\circ} \mathrm{C}$, kemudian temperatur coolant cenderung turun seiring dengan kecepatan putaran engine dari $85{ }^{0} \mathrm{C}$ hingga $82{ }^{\circ} \mathrm{C}$ pada putaran mesin $1500 \mathrm{rpm}$ hingga $3000 \mathrm{rpm}$. Hal ini mengindikasikan bahwa sejak putaran rendah sudah terjadi penyerapan panas yang baik. Sedangkan profile coolant predilute 33\% menunjukan pada putaran engine $600 \mathrm{rpm}$ temperaturnya sekitar $73{ }^{\circ} \mathrm{C}$ sedangkan temperatur engine yang tercatat pada engine scanner mencapai $94{ }^{\circ} \mathrm{C}$. Pada kecepatan putaran engine $1500 \mathrm{rpm}$ hingga $3000 \mathrm{rpm}$ temperatur coolant menunjukan kenaikan dari $76{ }^{\circ} \mathrm{C}$ hingga sekitar $80^{\circ} \mathrm{C}$ pada putaran engine $3000 \mathrm{rpm}$. Hal ini menunjukan bahwa pada kecepatan putaran rendah penyerapan panas oleh coolant Predilute 33\% tidak begitu besar tetapi temperatur mesin masih terjaga pada temperatur kerja mesin sekitar $94{ }^{\circ} \mathrm{C}$. Penyerapan panas oleh coolant baru terlihat ketika kecepatan engine dinaikan yang secara langsung juga meingkatkan kecepatan sirkulasi atau laju alir coolant ke mesin, sehingga temperatur coolant mencapai $82{ }^{\circ} \mathrm{C}$ pada kecepatan $3000 \mathrm{rpm}$.

Perbedaan yang dapat dilihat dengan penggunaan coolant 30/70 pre-mixed dan coolant predilute $33 \%$ adalah pada temperatur outlet engine dan inlet engine di mana temperatur coolant predilute $33 \%$ lebih rendah bila dibandingkan dengan temperatur coolant 30/70 pre-mixed. Tetapi temperatur engine tidak banyak perbedaan dengan pemakaian coolant $30 / 70$ pre-mixed maupun penggunaan coolant predilute $33 \%$.

\section{KESIMPULAN}

Adapun kesimpulan dari penelitian ini adalah sebagai berikut :

1. Berdasarkan data temperatur mesin dengan pemakaian coolant 30/70 pre-mixed pada berbagai variasi putaran mesin didapatkan temperatur rata-rata $94,13{ }^{\circ} \mathrm{C}$. Sedangkan pemakaian coolant predilute $33 \%$ terlihat temperatur rata-rata pada pengujian mencapai $94,4{ }^{\circ} \mathrm{C}$.

2. Berdasakan uraian hasil data pengujian yang sudah dilakukan, didapatkan kesimpulan bahwa penggunaan coolant $30 / 70$ pre-mixed maupun coolant predilute $33 \%$ mempunyai pengaruh yang sama terhadap temperatur engine Toyota Avanza tipe-E $1300 \mathrm{CC}$.

Sedangkan beberapa saran yang dapat diberikan adalah sebagai berikut :

Berdasarkan hasil uji coba dan hasil penelitian yang telah dilakukan pada engine Toyota Avanza Tipe-E 1300 CC MT, ada beberapa saran antara lain :

1. Sebelum melakukan pemakaian atau pemilihan coolant perlu dipertimbangkan komposisi coolant dan peruntukannya agar mendapatkan manfaat yang optimal.

2. Penggunaan coolant dengan campuran atau komposisi yang tepat merupakan salah satu jalan pilihan yang terbaik dalam upaya untuk mencegah kelebihan temperatur, adanya korosi dan kerusakan pada engine.

3. Pemilihan coolant sebaiknya juga mempertimbangkan sisi ekonomisnya.

4. Untuk penelitian selanjutnya dapat dicoba pada tipe atau campuran coolant yang berbeda. 


\section{UCAPAN TERIMA KASIH}

Terima kasih diucapkan kepada pihak Manajemen Laboratorium Program Studi Perawatan dan Perbaikan Jurusan Teknik Mesin Politeknik Negeri Samarinda

\section{DAFTAR PUSTAKA}

[1] N. L. H. Saragih, H. Maksum, "Pengaruh Variasi Cairan Pendingin (Coolant) Terhadap Efektivitas Radiator Pada Engine Diesel," Automotive Engineering Education Journal, vo. 2, no.2, 2017.

[2] D. R. Ariga, M. Martias, and T. Sugiarto, "Perbandingan Penggunaan Aditif Pada Sistem Pendingin Air Terhadap Tingkat Panas Mesin Mobil Toyota Avanza 1,3 GM/T," Automotive Engineering Education Journal, vol. 1, no. 2, 2015.

[3] D. A. D. Hersandi and I. Arsana, "Pengaruh Jenis Fluida Pendinginan terhadap Kapasitas Radiator pada Sistem Pendinginan Mesin Daihatsu Xenia 1300cc," Jurnal Pendidikan Teknik Mesin, vo. 06, no. 03, pp. 4152, 2018.

[4] W. Lestari, “Analisa Pengaruh Sistem Pendingin terhadap Mesin Bensin Xenia Type XI 1300 CC 4 Silinder 16 Valve (K3-De Dohc),” Jurnal Kajian Teknik Mesin, vol, 2, no. 1, pp. 52-60, 2017.

[5] Daryanto,' Reparasi Sistem Pendinginan Mesin Mobil. Jakarta: BUMI AKSARA, 2002.

[6] H.N. Gupta.," Fundamental of Internal Combustion Engines, 2006.

[7] Made Ricki Murti," Laju pembuangan panas pada radiator dengan fluida campuran 80\% air dan 20\% RC pada rpm konstan, Jurnal Ilmiah Teknik Mesin Cakram, vol.3, no.2, 2009.

[8] Gogineni. Prudhvi, Gada.Vinay, G.Suresh Babu," Cooling Systems in Automobiles \& Cars, International Journal of Engineering and Advanced Technology (IJEAT), Vol. 2, Issue-4, 2013

[9] Suharsimi Arikunto," Prosedur Penelitian Suatu Pendekatan Praktik, Jakarta: Rineka Cipta, 2006.

[10] Sugiyono,” Metode Penelitian Kuantitatif, Kualitatif, dan R\&D. Bandung: Alfabeta, 2013. 